\title{
O drama Epeu, de Eurípides
}

Wilson Alves Ribeiro Junior*

RESUMO: O objetivo deste artigo é, primeiro, avaliar os elementos do mito de Epeu que Eurípides pode ter utilizado para o enredo do drama homônimo; segundo, traduzir e comentar brevemente a única possível fonte desse misterioso drama, perdido possivelmente antes de ser preservado na Biblioteca de Alexandria; e, finalmente, discutir a possibilidade de se tratar de um dos poucos dramas satíricos criados por Eurípides durante a segunda metade do século V a.C.

Palavras-chave: Eurípides; drama satírico; teatro grego; Epeu; fragmentos.

ABSTRACT: The purpose of this paper is, first, to evaluate the elements of Epeus myth that Euripides may have used for the plot of the eponymous drama; secondly to translate, with a brief commentary, the only possible source of this mysterious drama, lost perhaps before preservation in the Alexandrian Library; and finally to discuss its possibilities of being one of the few satyric dramas created by Euripides during the second half of the fifth century BC.

Keywords: Euripides; satyric drama; Greek theatre; Epeius; fragments.

O drama intitulado Epeu (gr. 'Enєıós) ${ }^{1}$ é mencionado nos catálogos de dramas euripidianos; faltam-nos, porém, referências e evidências sobre sua natureza, enredo e data. Acredita-se, desde Wilamovitz (PECHSTEIN, 1998, p. 141, n. 7), que Eреи era um dos dramas satíricos já perdidos antes da época da Biblioteca de Alexandria, quando os dramas euripidianos foram coligidos e editados pela primeira vez.

\section{O mito de Epeu ${ }^{2}$}

O título do drama não se refere a Epeu, filho de Endimíon, que se tornou rei da Élida ao vencer os irmãos em corrida disputada em Olímpia (PAUSÂNIAS 5.1.4); trata-

\footnotetext{
* Doutor e Mestre em Letras Clássicas pela Universidade de São Paulo.

${ }^{1}$ Lat. Epēus ( $\varepsilon_{1}>\bar{e}$, cf. VIRGílLIO, Eneida 2.264 e HIGINO, Fábulas 108) ou Epīus (cf. PLAUTO, Báquides 937). Há uma certa controvérsia entre tradutores portugueses e brasileiros da Ilíada, da Odisseia, da República de Platão e de Troianas de Euripides quanto à transcrição do nome, e alguns usaram até mesmo soluções diversas em diferentes traduções: "Epeu” (Jaime Bruna, Christian Werner, Frederico Lourenço, Eleazar Magalhães Teixeira, Anna Lia Amaral de Almeida Prado), "Epeio" (Carlos Alberto Nunes, Maria Helena da Rocha Pereira, Trajano Vieira, Frederico Lourenço), "Epeios" (Christian Werner) e "Épio" (Donaldo Schüler). Adotei a forma "Epeu" por ser a mais próxima da versão latina tradicional, através da qual a maioria das palavras gregas chegou ao português.

${ }^{2}$ Principais fontes literárias anteriores a 400 a.C.: Ilíada (23.664-99; 838-40), Odisseia (8.492-3; 11.523), Pequena Ilíada (arg. 4), Ásio (Fr. 5), Estesícoro (Fr. 200 = Ateneu 10.84.34-9; S 89), Eurípides (Troianas, 9-14), Fr. cômico adesp. 952. Posteriores: Platão (Ion 533a; República 620c), Símias de Rodes (Fr. 25 = Um machado), Calímaco (Fr. 167 = Iambo 7), Lícofron (930-1). Fontes iconográficas mais antigas: Florença 96780, Polignoto (Saque de Ílion = Paus. 10.26.2), possivelmente Munique 2650.
} 
se provavelmente de Epeu, filho de Panopeu (Ilíada 23.665; Ásio Fr. 5), o construtor do cavalo de Troia. Eurípides fala dele no prólogo de Troianas (9-14):

$$
\text { o parnassiano }
$$

Epeu, da Fócida ${ }^{3}$, pelos estratagemas de Palas um cavalo prenhe de armas construiu e enviou para dentro das muralhas $(. . .)^{4}$

O mito do fócio Epeu, a quem Atena inspirou o estratagema que conquistaria Troia (Od. 8.493), remonta aos poemas homéricos. A Ilíada naturalmente não menciona o cavalo, construído no último ano da guerra, tempos depois da morte de Aquiles. Ao descrever os jogos promovidos por ele após a morte de Pátroclo, porém, Homero conta

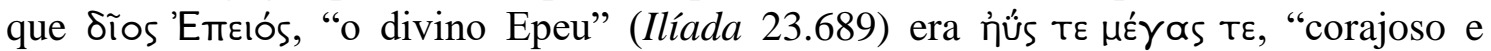
grande", excelente pugilista, péssimo arremessador de pesos e inferior aos demais no combate (664-9), o que aliás ele mesmo reconhecia (670-1). Note-se que o prêmio

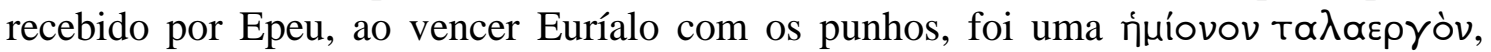
"incansável mula" (662), o que sinaliza algum vínculo antigo entre ele e cavalos (ZACHOS, 2013, p. 6). Na Odisseia, na Pequena Ilíada de Lesques e no Saque de Troia de Estesícoro ${ }^{5}$ (Fr. S89), poemas posteriores à Ilíada, Epeu é lembrado primordialmente pela construção do cavalo de madeira, o que de certo modo evoca a destreza manual que demostrou ao vencer o pugilato. Essas habilidades são mostradas graficamente em estano etrusco de figuras negras (c. 500 a.C., Florença 96780) ${ }^{6}$, que mostra Epeu (identificado por inscrição) completando uma cabeça de cavalo ao lado de várias ferramentas. O cálice ático de figuras vermelhas do Pintor da Fundição (Vulci, c. 480 a.C., Munique 2650) que mostra Atena, um artesão com suas ferramentas e um cavalo (talvez apenas um modelo) diante de um homem sentado sob uma árvore (Agamêmnon?), talvez represente Epeu e o cavalo de Troia ${ }^{7}$.

Homero deixou razoavelmente claro, na Ilíada, que Epeu tinha origem nobre e

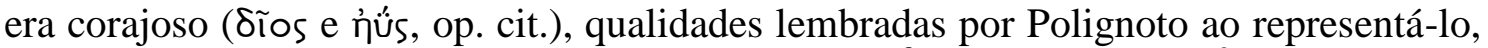
em meados do século V a.C. (PAUSÂNIAS 10.26.2) ${ }^{8}$, heroicamente nu ${ }^{9}$ ao derrubar as muralhas de Troia diante de gigantesco cavalo (Fig. 1):

\footnotetext{
${ }^{3}$ O Monte Parnasso (2.457 m) é parte de elevado complexo montanhoso ao norte do Golfo de Corinto. Na encosta meridional fica a antiga Delfos e a maior extensão de suas bem irrigadas encostas fica a leste, na Fócida.

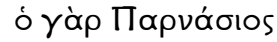

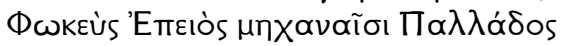

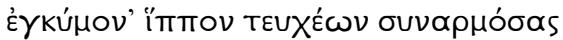

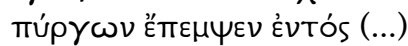

${ }^{5}$ Há outros poemas com o mesmo título: um do Ciclo Épico, atribuído a Arctino de Mileto e que sobreviveu em fragmentos, e outro de Sacadas de Argos, conhecido apenas por uma referência de Ateneu (13.91).

${ }^{6}$ Florença, Museu Arqueológico, inv. 96780; para a imagem, ver Lewis (2010, p. 19, fig. 19).

${ }^{7}$ Munique, Coleções Estatais de Antiguidades, inv. 2650. Imagem disponível no Portal Graecia Antiqua, <greciantiga.org/img.asp?num=1243>. Acesso em: 11/12/2017, domínio público. Para a identificação do artífice com Epeu, ver Zachos (2013, p. 12, n. 53).

${ }^{8}$ Essa pintura, datada de 458-447 a.C. e intitulada Saque de Troia, é conhecida apenas pela detalhada descrição de Pausânias (10.25-31). Ela decorava uma das paredes internas do $\lambda$ Éoxワ dos Cnidianos (edifício para abrigar cidadãos de Cnidos) ao norte do templo de Apolo em Delfos.

${ }^{9}$ Convenção utilizada amiúde pelos decoradores de vasos e escultores da Antiguidade para representar heróis e, às vezes, divindades.
} 


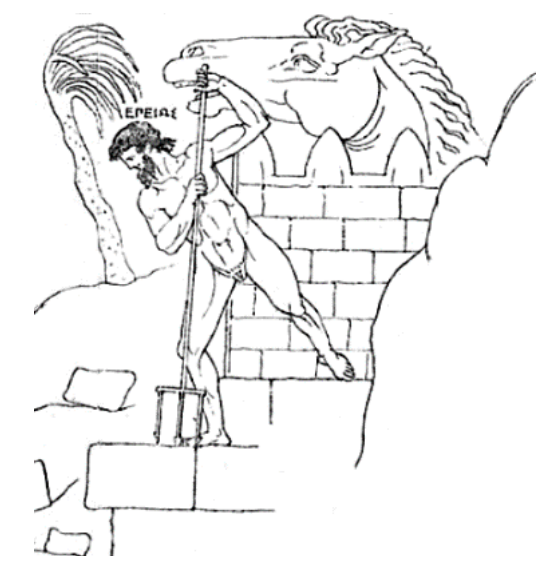

Figura 1. Epeu e o cavalo de Troia. Pequeno trecho da reconstrução conjetural de pintura de Polignoto no $\lambda \varepsilon ́ \sigma \times \eta$ dos cnidianos em Delfos, 458-447 a.C. Desenho de Herman Schenck (ROBERT, 1893, tafel), ligeiramente editado pelo autor ${ }^{10}$.

Havia, no entanto, outras tradições relativas a ele: o poeta Estesícoro conta, em outra

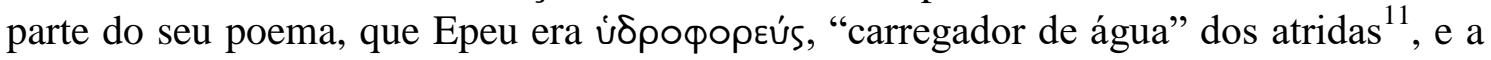
deusa Atena se compadecia dele (Fr. 20); mais tarde, no final do século V a.C., um fragmento cômico (Fr. adesp. 952) conservado por Zenóbio e outros autores tardios

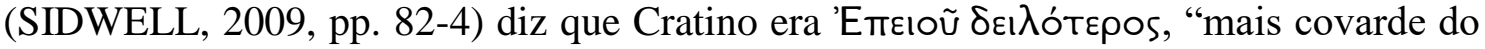
que Epeu". Nos poemas homéricos, Epeu não se destacou como guerreiro, mas isso não significa necessariamente que ele era covarde ou encarregado de tarefas servis. Talvez a

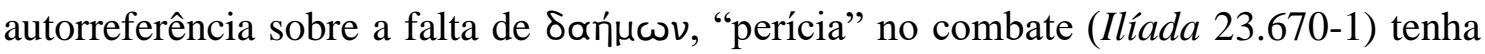
se tornado tema de comédia e, graças a isso, seu nome começou a evocar esse tipo de lembrança.

No século IV a.C., depois da época de Eurípides, Platão chamou-o de "escultor" no Íon e o colocou lado a lado com outro lendário artífice, Dédalo ${ }^{12}$, mas na República, ao descrever a escolha de novas vidas pelas almas dos que já haviam morrido ${ }^{13}$, contou que a alma de Epeu escolheu a vida de mulher versada em artesanato. A escolha da alma feminina certamente reflete a crença dos antigos gregos de que mulheres, embora inferiores aos homens, são particularmente afeitas ao engano, e o ardil do cavalo de Troia é um dos mais acabados exemplos de engano da literatura grega ${ }^{14}$. No século III a.C., Símias de Rodes reiterou, em poema a ele atribuído (Fr. 25.5), que Epeu não era contado entre os que combatiam à frente dos aqueus; Calímaco (Fr. 167.2-3) fez uma

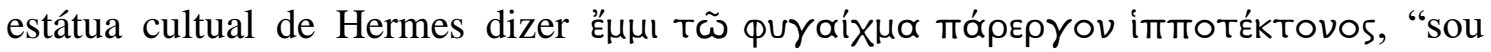
obra secundária do covarde criador do cavalo (de Troia)"; e Lícofron afirmou, na Alexandra, que ele vivia com medo. Assim, o tema da "covardia" de Epeu se transmitiu aos autores greco-romanos posteriores, mas não de forma homogêna; Virgílio conta, na

\footnotetext{
${ }^{10}$ Fonte: Universitätsbibliothek Heidelberg. Disponível em: 〈www.ub.uni-heidelberg.de〉. Acesso em: 11 dez. 2017. Licença Creative Commons BY-SA 3.0.

${ }^{11}$ Menelau e Agamêmnon, filhos de Atreu. Eles usualmente são mencionados assim na qualidade de comandantes dos exércitos gregos em Troia, embora, a rigor, somente Agamêmnon detinha essa função.

${ }^{12}$ Ao legendário Dédalo eram atribuídas técnicas, inovações e utensílios cuja origem se perdera no tempo (e.g. Platão, Hipias Maior 282a). Eurípides mencionou ou explorou as tradições míticas sobre ele no drama satírico Euristeu (Fr. 372) e nas tragédias Hécuba (836-8), Os cretenses (Fr. 968) e, possivelmente, Teseu (Fr. 390).

${ }^{13} \mathrm{O}$ mito de Er (620a-621d). Para breve, mas elucidativo panorama desse mito platônico, ver introdução de Maria Helena da Rocha Pereira para sua tradução do diálogo República (1996, p. xxxix-xlv).

${ }^{14}$ Ver Ribeiro Jr. (2011) sobre o engano do cavalo de Troia (pp. 65-6, 99-10, 121 e 198) e sobre o tema do sexo feminino e engano (p. 347-51).
} 
Eneida (2.264), que ele era um dos gregos escondidos dentro do cavalo de Troia.

Além do Epeu de Eurípides, nenhum outro drama parece ter sido inspirado pelo mito.

\section{Fontes do drama ${ }^{15}$ e comentários}

Do drama Epeu restam o título, EПE〈I〉O $\Sigma$, talvez $E \Pi H O \Sigma^{16}$, e um único e

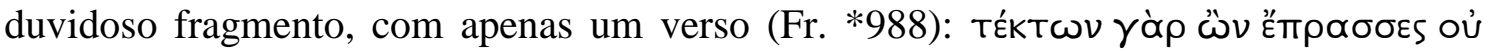

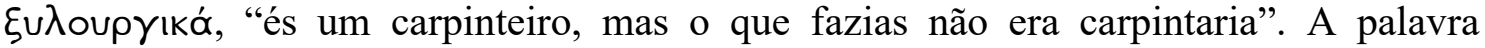

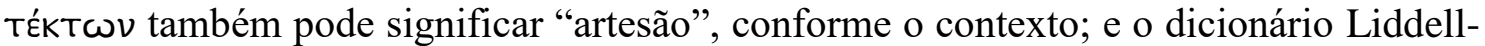

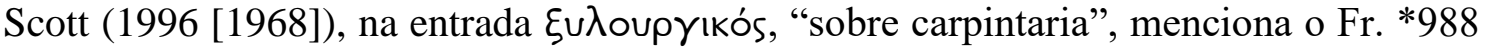

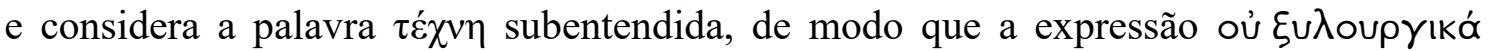
poderia ser traduzida igualmente por "não fazia parte da arte da carpintaria".

O fragmento foi conservado por Plutarco (Preceitos para a ciência de governar, 812e) ao citar Eurípides, sem mencionar a obra, quando discorre a respeito de pessoas que têm sede de poder e se dispõem a ter encargos, na pólis, para os quais não estão preparadas, e atribuído ao drama Epeu por Welcker (1839, p. 523). Outras atribuições possíveis: Kpñoođı (As cretenses), em passagem atribuída a Minos, que se dirige a Dédalo; Collard (2009, p. 78) considera essa última atribuição a mais provável.

\section{Reconstruindo Epeu}

Não há informações nas fontes literárias sobre esse drama e, por isso, tanto o enredo quanto sua real natureza, trágica ou satírica, continuam completo mistério. Pechstein (1998, p. 142) acredita que se trata de drama satírico e justifica sua hipótese de forma elaborada, aludindo notadamente à posição do título no catálogo, em relação aos outros títulos satíricos registrados no marmor albanum, na coluna I (Autólico, linha 13; Busíris, linha 16; Euristeu, linha 24; Epeu, linha 25) e na coluna II (Ciclope, linha 4). Kannicht (2004, v. 5.1, p. 390) e Collard e Cropp (2008, p. 361) simplesmente consideram Epeu personagem apropriado para dramas satíricos, especificamente por causa das fontes que mencionam sua "covardia"; Collard e Cropp (op. cit.) lembram ainda a possibilidade de a construção do cavalo de Troia ser também parte do drama, o que estaria decididamente confirmado somente se o Fr. $* 988$ pertencesse realmente ao Epeu.

Kannicht (op. cit.) apresentou uma citação para justificar seu argumento: a

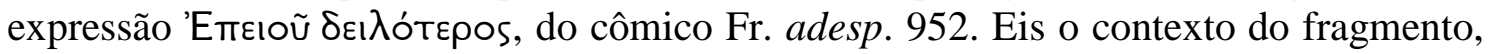
na versão de Zenóbio (3.81):

Mais covarde do que Epeu: isso é o que diziam do poeta cômico Cratino, talvez porque ele foi taxiarca da tribo ${ }^{17}$ dos Eneídas ${ }^{18}$ e se mostrado muito covarde; pois Epeu era covarde. ${ }^{19}$

\footnotetext{
${ }^{15}$ Testemunho e fragmento: Kannicht (2004, v. 5.1, p. 58 e 390; v. 5.2, p. 975). Visão geral do drama: Pechstein (1998, p. 141-4), Van Looy (2002, pp. 93-4) e Collard e Cropp (2008, p. 361). Não há iconografia associada ao drama, somente ao mito.

${ }^{16}$ Catálogo I = IG XIV $1152 \mathrm{col}$ I 25. Marmor albanum, Paris, Museu do Louvre (inv. Ma 343), século II.

${ }^{17} \mathrm{O}$ taxiarca era o comandante de uma tropa de soldados da infantaria. Durante o Período Clássico, em Atenas, havia dez taxiarcas, um para cada tribo ( $\left.\phi \cup \lambda)^{\prime}\right)$.

${ }^{18}$ Eneídas: literalmente, "descendentes de Eneu” (gr. Oiveús). O nome tem relação direta com ò oĩvos, "o vinho" (cf. vocábulos enólogo, enologia), e Cratino tinha reputação de beber muito (Cratino, test. xi).

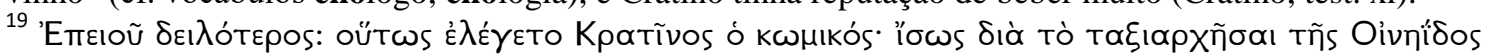

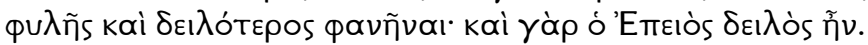


Os sátiros são, eles mesmos, covardes por natureza (e.g. Eurípides, Ciclope 624-53); será que o Fr. adesp. 952 se refere a eles, que seriam ainda mais covardes do que Epeu? A possibilidade de essa passagem ter relação com o enredo do Epeu é, realmente, muito tênue. A rigor, o mito de Epeu não contém nenhum elemento que possa ser indubitavelmente vinculado a um drama satírico, nem mesmo o tema da covardia; vejase, por exemplo, o caso de Egisto, instigador da morte de Agamêmnon (Odisseia, passim $)^{20}$, tratado como uma espécie de covarde em tragédias de Ésquilo, Sófocles e Eurípides.

Parece-me que o instinto dos eruditos, mais do que os argumentos apresentados por eles, é o que dá mais peso à possibilidade de Epeu ser drama satírico, e não uma tragédia.

\section{REFERÊNCIAS}

COLLARD, Christopher. Cretans. In: COLLARD, C.; CROPP, M.J. e LEE, K.H. Euripides selected fragmentary plays, v. 1, with corrections and addenda. Oxford: Oxbow (Aris \& Phillips), 2009, pp. 53-78.

COLLARD, Christopher e CROPP, Martin. Euripides fragments, vol. 1. Cambridge MA / London: Harvard University Press, 2008.

KANNICHT, Richard. Tragicorum graecorum fragmenta (TrGF), v. 5.1 (pars prior) e v. 5.2 (pars posterior). Göttingen: Vandenhoeck \& Ruprecht, 2004.

LIDDEL, H.G. e SCOTT, R. A Greek-English Lexicon with Supplement, ${ }^{\text {th }}$ ed. (1968; suppl. in 1996), revised by H.S. Jones and R. McKenzie. Oxford: Oxford University Press, 1996.

LEWIS, Sian. Images of Craft on Athenian Pottery: Context and Interpretation. Bollettino di Archeologia on line, Roma, v. speciale, C / C4 / 3, 2010. Disponível em bollettinodiarcheologiaonline.beniculturali.it/documenti/generale/3_LEWIS.pdf.

Consultado em 13/12/2017.

PECHSTEIN, Nikolaus. Euripides satyrographos: ein Kommentar zu den Euripideischen Satyrspielfragmenten. Stuttgart / Leipzig: Teubner, 1998.

RIBEIRO JR., Wilson Alves. Enganos, enganadores e enganados no mito e na tragédia de Eurípides. Tese de Doutoramento em Letras Clássicas. São Paulo: Universidade de São Paulo, 2011.

ROBERT, Carl. Die Iliupersis des Polygnot. Halle: Niemeyer, 1893.

ROCHA PEREIRA, Maria Helena da. A República. Platão, $8^{\mathrm{a}}$ ed. Lisboa: Calouste Gulbenkian, 1996.

\footnotetext{
${ }^{20}$ A história da morte de Agamêmnon, rei de Argos, às mãos de sua esposa Clitemnestra e de seu primo Egisto, amante dela, foi contada na Odisseia, embora de forma um pouco "espalhada": 1.29-30, 35-43, 46-7, 298-300; 3.193-8, 232-35, 248-75 e 303-10; 4.512-37 e 4.545-7; 11.387-464; 24.19-22, 96-7 e 199202.
} 
SIDWELL, Keith. Aristophanes the Democrat: The Politics of Satirical Comedy during the Peloponnesian War. Cambridge: Cambridge University Press, 2009.

VAN LOOY, Herman. EחE〈I $\bigcirc \Sigma$ - Épéios. In: JOUAN, François e Euripide, tragédies tome VIII $2^{e}$ partie: fragments de Bellérophon à Protésilas. Paris: Les Belles Lettres, 2002, pp. 93-4.

WELCKER, Friedrich Gottlieb. Die griechischen Tragödien mit Rücksicht auf den epischen Cyclus, v. 2 (Euripides). Bonn: Weber, 1839.

ZACHOS, Georgios A. Epeios in Greece and Italy. Two Different Traditions in One Person. Athenaeum, Pavia, v. 101, n. 1, 2013, pp. 5-23.

Data de envio: 16-03-2018

Data de aprovação: 16-04-2018

Data de publicação: $15-08-2018$ 